\title{
Analysis of Fouled RO Membranes Using Analytical STEM
}

D. H. Anjum ${ }^{*}$, R. Sougrat ${ }^{* *}$, K. Hooghan ${ }^{*}$, M. T. Khan ${ }^{* *}$, J. P. Croue ${ }^{* *}$ and A. R. Behzad ${ }^{* *}$

*FEI Company, 5350 NE Dawson Creek Dr., Hillsboro, OR, 97124

**4700 King Abdullah University of Science \& Technology (KAUST), Thuwal, 23955, Kingdom of Saudi Arabia (KSA)

Reverse Osmosis (RO) based membranes are commonly used for water desalination at the industrial scale but these are prone to fouling due to the accumulation of organic (biofouling) and inorganic (colloidal fouling) materials [1]. Currently, several methods are in use to characterize at nano-scale surface morphology and composition of cake layers on membranes. However, a thorough investigation of fouling mechanisms including the progression of cake layer also requires cross-sectional analysis of the membranes. The purpose of the study is to characterize the cross sections of fouled membranes using the combined techniques of scanning transmission electron microscopy (STEM) and energy dispersive spectroscopy (EDS). Fouled RO membrane from a pilot scale module fed with treated urban waste water was harvested and freeze dried. Cross sections of freeze dried membrane were prepared using a dual beam SEM (Quanta3D-FEG, FEI Company) [2]. A $300 \mathrm{kV}$ TEM equipped with STEM (Titan $\mathrm{G}^{2}$ S/TEM, FEI Company) and EDS detectors (EDAX system) was used to image the bio-fouled membrane in cross section and to determine the composition of elements present in cake layers.

Dark-Field STEM analysis showed a non-uniform cake layer that contained fouling materials (Fig. 1A and 1B). The differential contrast observed in the STEM images allowed identifying the high density colloidal particles that were embedded in the cake layer. EDS spot analysis in the STEM mode showed the colloidal particles were made of metals including $\mathrm{Zn}, \mathrm{Fe}, \mathrm{Cr}$ and possibly $\mathrm{Cu}$ (Fig. 2). In addition, EDS spot analysis on non-colloidal regions of cake layer showed non-metal elements such as $\mathrm{C}, \mathrm{N}, \mathrm{P}$ and $\mathrm{S}$ (Fig. 2). In conclusion, FIB-prepared STEM-EDS analysis of bio-fouled membrane allowed better 
understanding of internal structure of cake layer at nano-scales as well as the spatial relationship of foulants with respect to the membrane.
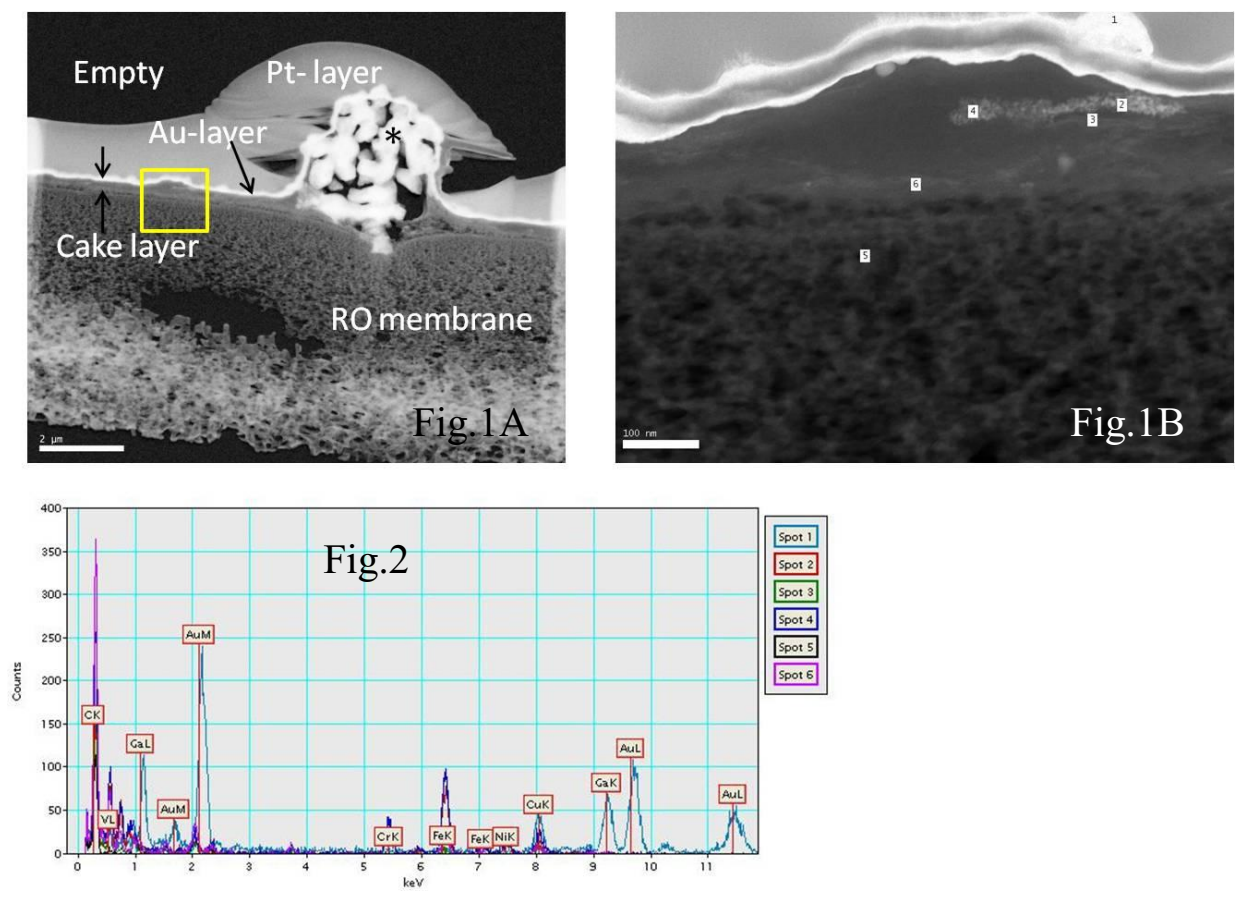

Fig. 1A: A typical dark-field STEM image of a cross section profile of fouled membrane prepared by FIB showing the non-uniform cake layer with embedded colloidal particles $(*)$.

Fig.1B: A higher magnification of boxed area in Fig.1A used for EDS spot analysis.

Fig.2: Overlaid EDS spectra acquired from 6 spots in Fig.1B showing various elemental peaks coming from five points shown in the Fig.1B.

\section{References}

[1] D. Paul et al., Ultra Pure Water, vol. 7, No 3, pp 25-36, (1990).

[2] A. R. Behzad et al., M \& M Conference 2011, Nashville, TN. 